\title{
DE QUE FORMA A LEI DO BEM INCENTIVA A ATIVIDADE INOVATIVA DAS FIRMAS? UMA REFLEXÃO PARA EMPRESAS SELECIONADAS NO RIO GRANDE DO SUL
}

FABIANE PADILHA

Mestre em Economia

Universidade do Vale do Rio dos Sinos (UNISINOS)

fabipadilha@terra.com.br

JANAINA RUFFONI

Professora do Programa de Pós-Graduação em Economia Universidade do Vale do Rio dos Sinos (UNISINOS)

jruffoni@unisinos.br

\section{RESUMO}

O estudo objetiva compreender a influência da Lei do Bem na atividade inovativa da firma. Para tanto, foi realizado um estudo exploratório de múltiplos casos em firmas industriais do Rio Grande do Sul em 2015. Como resultados principais destacam-se: a tomada de decisão por inovar é determinada pela dinâmica de mercado e disponibilidade de recursos próprios das firmas; o uso do incentivo fiscal foi compreendido como um estimulador (e não determinante) à manutenção das atividades inovativas, as quais já faziam parte da rotina das firmas antes mesmo da obtenção do incentivo público; e não ficou demonstrada explicitamente a existência de um efeito de 'soma’ de recursos públicos e privados pelas firmas para a geração da inovação.

Palavras-chave: Incentivo Fiscal à Inovação. Inovação da Firma. Lei do Bem.

\begin{abstract}
The study aims to understand the influence of 'Lei do Bem' on innovative activity of the firm. Therefore, we performed a multiple case exploratory study in industrial firms of Rio Grande do Sul in 2015. The main results are: decision making for innovation is determined by market dynamics and availability of financial firm's resources; the use of the tax incentive was understood as a stimulator (not determinant) the maintenance of innovative activities, which were already part of the firm's routine before obtaining public incentives; and it was not explicitly demonstrated the existence of a 'sum' effect of public and private resources for firm’s generating innovation.
\end{abstract}

Keywords: Tax Incentives for Innovation. Firm’s Innovation. 'Lei do Bem’.

Área 8

Classificação JEL: L2, O31 e O32. 


\section{DE QUE FORMA A LEI DO BEM INCENTIVA A ATIVIDADE INOVATIVA DAS FIRMAS? UMA REFLEXÃO PARA EMPRESAS SELECIONADAS NO RIO GRANDE DO SUL}

\section{Introdução}

Este artigo objetiva compreender a influência dos incentivos fiscais da Lei do Bem para a atividade inovativa de firmas industriais. Parte-se do pressuposto que o uso de incentivos fiscais para a realização da atividade inovativa é benéfico por permitir à firma usufruir de recursos financeiros adicionais, além dos privados, e investir no estabelecimento de rotinas e processos que permitam uma melhor execução da sua atividade inovativa.

O desenvolvimento de um ambiente favorável à dinamização do processo de inovação tecnológica nas empresas é elemento importante nas agendas governamentais. Isso justifica-se, pois, de acordo com Avellar (2007, p. 23), “o ritmo com que ocorrem as inovações tecnológicas, na maioria das vezes, determina a taxa de ampliação da produtividade dos fatores de produção e o processo de criação de novos mercados, estimulando o crescimento da economia”.

No caso do Brasil, a Pesquisa de Inovação (PINTEC) ${ }^{1}$ destaca, dentre os obstáculos à inovação, os riscos econômicos excessivos (SALERNO e KUBOTA, 2008, p. 38). Para minimizar as influências das adversidades na tomada de decisão do empresário na busca pela inovação, criam-se instrumentos para fomentar a inovação. Um desses aparelhos é a denominada 'Política Pública de Incentivos Fiscais à Inovação’, onde se insere a Lei 11.196 de Novembro de 2005 (BRASIL, 2006), ou, como doravante será denominada, "Lei do Bem", que foi regulamentada pelo Decreto $n^{\circ}$ 5.798, de 07 de Junho de 2006 e possui a Instrução Normativa da Receita Federal n 1.187/11 para discipliná-la (RFB, 2011). Seu objetivo é o de beneficiar as empresas que assumem gastos com Pesquisa, Desenvolvimento e Inovação (PD\&I). A utilização da Lei é uma opção da empresa, entretanto, para receber os benefícios, a firma deve ser tributada pelo 'lucro real', estar em dia com suas obrigações fiscais e preencher o documento 'Formulário para Informações sobre as Atividades de Pesquisa Tecnológica e Desenvolvimento de Inovação Tecnológica' (FORMP\&D) e encaminhá-lo ao Ministério da Ciência, Tecnologia e Inovação (MCTI, 2013).

Considerando, portanto, que inovar é fundamental para as firmas e que incentivos públicos fiscais existem para estimular as firmas a realizarem a inovação, parte-se do pressuposto neste trabalho de que o uso de incentivos fiscais para a realização da atividade inovativa é benéfica por permitir à firma usufruir de recursos adicionais, além dos privados, para investir no estabelecimento de rotinas e processos que permitam uma melhor execução da sua atividade inovativa. Sendo assim, a questão de pesquisa que emerge é: quais são os benefícios para a atividade inovativa da firma pelo uso de incentivos fiscais?

O estado do Rio Grande do Sul (RS) ocupa o segundo lugar no país na utilização da Lei do Bem. Para melhor compreender a relação entre o uso do incentivo fiscal e a geração de inovações pelas firmas foi realizado um estudo exploratório de múltiplos casos em 2015 em firmas industriais selecionadas no Rio Grande do Sul que foram beneficiada pela Lei do Bem entre 2006 e 2012.

O artigo está organizado em cinco seções, além desta Introdução. Na seção 2 encontra-se uma revisão teórica a respeito do uso de incentivos públicos fiscais para estimular a atividade inovativa da firma. Os procedimentos metodológicos encontram-se descritos na seção 3 . Na seção 4 apresenta-se a descrição e análise dos dados e, por fim, na seção 5 são expostas as considerações finais.

\section{Incentivos Públicos e Inovação}

Pela relevância que a inovação assume, os incentivos fiscais se apresentam como uma alternativa de política pública para estimular a iniciativa privada no incremento da atividade inovativa. Essa, por sua vez, é inerentemente arriscada, mas uma ferramenta essencial para a obtenção de vantagem competitiva pela firma.

\footnotetext{
${ }^{1}$ Realizada pelo Instituto Brasileiro de Geografia e Estatística (IBGE) e com resultados divulgados desde o ano de 2000 até 2011.
} 
Marcovitch et all (1991, p. 43) afirmam: "O fomento à inovação tecnológica tem se constituído, cada vez mais, numa preocupação dos governos, tanto nos países desenvolvidos como naqueles em desenvolvimento. Dentre as formas mais utilizadas destacam-se os incentivos fiscais”.

No cenário internacional pode-se observar que as políticas de Ciência, Tecnologia e Inovação (CT\&I) vêm ganhando cada vez mais espaço nas agendas governamentais (LEMOS e CÁRIO, 2013).

É fato conhecido que, no atual cenário internacional, o crescimento sustentado de uma economia depende da competitividade dos seus produtos e processos. Para a indústria, além das condições macroeconômicas favoráveis aos investimentos, a competitividade dos seus produtos também depende do conteúdo tecnológico, não só para assegurar produtividade, mas também para atender às demandas dos seus consumidores e usuários. (WEIZ, 2006, p. 10).

Avellar (2007) analisou estudos relativos à avaliação dos efeitos dos incentivos fiscais sobre empresas beneficiárias. Objetivando responder se 'o gasto público é capaz de estimular o gasto privado em P\&D' foi considerada a existência de dois fenômenos: o primeiro chamado efeito crowding out (efeito substituição) e o segundo definido efeito additionality ou crowding in (efeito alavancagem). (ARAÚJO, 2012). O efeito crowding out daria-se quando "as empresas investiriam em P\&D o mesmo montante que o fariam na ausência do instrumento, e os incentivos públicos apenas substituiriam recursos privados" (AVELLAR, 2008). Tratando desse efeito, Zucoloto (2009, p. 90) considera-o como um "prêmio ao empresário que busca a inovação”. Rocha (2015) através de sua pesquisa destacou que o apoio governamental não parece afetar positivamente os gastos em $\mathrm{P} \& \mathrm{D}$, pois os investimentos teriam ocorrido mesmo sem a interferência governamental.

Avellar (2008a, p. 19) aponta outra característica: “o incentivo seria apenas uma forma de redução de custos”. Nesse caso, o empresário não realoca o valor da redução fiscal para a atividade inovativa, ele classifica-o como aumento de lucro. A conclusão é que, o efeito crowding out, nesse aspecto, mostra-se contrário ao objetivo da política, pois não há a promoção da inovação e, se os empresários virem esse estímulo apenas como uma redução de gastos, a Lei do Bem não estará cumprindo seu papel, mostrandose apenas como um gasto para a máquina pública. Assim:

Consequentemente, as políticas serão ineficazes se houver crowding out, seja ele completo ou parcial. No caso parcial, as empresas substituem apenas parte dos seus gastos e no caso completo, as empresas substituem 100\% dos gastos em P\&D pelo montante oferecido pelo Governo. (ALVARENGA, 2011, p. 35).

Porém, quando há, efetivamente, estímulo às empresas no que tange os gastos em inovação, acontece o efeito additionality (ou crowding in). Esse fenômeno mostra que a política, de fato, atingiu seu objetivo, pois foi capaz de estimular o gasto privado, fazendo com que um montante maior do que aquele realizado sem a presença de tal programa fosse direcionado à atividade inovativa, conforme segue:

Se o programa público de incentivo à inovação estimula as empresas a gastarem em atividades inovativas um montante superior ao previamente alocado pode-se concluir que a intervenção do governo foi capaz de ampliar o gasto privado, constituindo-se assim o chamado "efeito additionality" (efeito alavancagem) pelo fato dos gastos públicos e privados não serem substitutos, mas sim estimularem um gasto privado maior do que aquele que seria realizado sem a presença de tal programa. (AVELLAR, 2008a, p. 19).

Assim, o investimento feito pelo governo provocaria um efeito catalisador nos próximos investimentos, fazendo com que o objetivo da política fosse confirmado e o mecanismo realmente fosse eficaz em sua finalidade.

Contudo, as avaliações dos efeitos não são as únicas formas de demonstrar se os resultados da política estão sendo alcançados. Outros quatro estudos mostram-se condizentes: Guimarães (2008), Luna, Moreira e Gonçalves (2008), Salerno e Kubota (2008) e Castro et al (2012). 
Guimarães (2008) examina a evolução e as características atuais das políticas de incentivo fiscal e financeiro às atividades de $\mathrm{P} \& \mathrm{D}$ adotadas por países da Organização para Cooperação e Desenvolvimento Econômico (OCDE), concluindo que dos 24 países analisados apenas 7 não oferecem nenhum benefício fiscal aos gastos com $\mathrm{P} \& \mathrm{D}$, outros oferecem em menor grau e na Noruega os incentivos fiscais são significativamente mais generosos que nos demais países.

Luna, Moreira e Gonçalves (2008) fazem um resumo das políticas de financiamento e incentivo à inovação, avaliando as práticas internacionais visando à formulação de políticas públicas que resultaram em aumento do esforço de inovação. Eles concluem, por meio da análise das experiências internacionais, que a focalização das iniciativas é característica marcante em sistemas de inovação, onde existem benefícios indiretos, como a absorção de trabalhadores em pequenas e médias empresas e também como agentes de transferência de tecnologia do sistema acadêmico.

Salerno e Kubota (2008) falam do panorama internacional frente às políticas industriais de inovação recentes, onde frisam que alguns países (a exemplo de Japão, Coréia do Sul, França e Finlândia) caminham para a terceira geração em políticas de inovação. Essa terceira geração em políticas de inovação propõe uma integração maior entre as políticas de inovação e outras políticas - como a ambiental, a de educação e a de saúde. A primeira geração seria aquela baseada no processo linear (da pesquisa básica para a pesquisa aplicada e, daí, para a introdução no mercado de novos produtos e tecnologias) e a segunda geração é identificada com o conceito de Sistemas Nacionais de Inovação (SNI).

Castro et al (2012) fizeram um estudo do panorama de incentivos governamentais no Canadá, China, Estados Unidos e Rússia. Os autores constataram que nos três primeiros países já havia políticas públicas que estimulavam áreas relacionadas à ciência e tecnologia (C\&T), oferecendo crédito tributário ou outros incentivos, o que não ocorreu na Rússia que, ao contrário das três nações anteriores, mostra um setor privado inativo e isolado.

\section{Políticas de Ciência, Tecnologia e Inovação no Brasil e a Lei do Bem}

Observa-se que a trajetória do Brasil, nas questões relacionadas à C\&T e, mais recentemente, à Inovação, (CT\&I) mostra-se como um caminho que "remonta à própria história do país” (LEMOS, 2013, p. 2).

Suzigan e Albuquerque (2008) apontam a existência de ondas de formação das instituições de ensino e pesquisa no Brasil ao mesmo tempo de que Viotti (2008) apresenta uma distinção em fases, onde a terceira fase é aquela que o autor classifica como 'em busca do desenvolvimento via inovação', que iniciou na virada do século e ainda está em transcurso.

Salles Filho (2002) publicou na Revista Brasileira de Inovação (RBI) uma série de textos onde se relembraram ações que foram essenciais para a sequência das Políticas Públicas relacionadas à C\&T. Revisitando o I Plano Nacional de Desenvolvimento ${ }^{2}$ (PND), onde origina-se o I Plano Básico de Desenvolvimento Científico e Tecnológico (PBDCT), e, posteriormente, o II PBDCT e o III PBDCT.

Salles Filho (2003a, p. 407) afirma que os "os PBDCT revelam uma fase em que havia planejamento integrado”. Havia uma visão sistêmica do funcionamento da C\&T no país, com ações programadas, orçamento e revisões anuais. Porém, Suzigan e Albuquerque (2008, p. 16) retratam o quadro da C\&T:

Um fato notável, do ponto de vista de instituições coordenadoras, é que somente em 1985, após o fim do regime militar, o país passa a ter um Ministério da Ciência e Tecnologia. Entretanto, o MCT, e todas as instituições de financiamento e de apoio ao desenvolvimento científico e tecnológico, enfrentaram séria crise até meados da década de 1990.

\footnotetext{
${ }^{2}$ O PND visava à aplicação de uma política multiforme de desenvolvimento econômico, que estabelecia metas e linhas de ação coordenadas para o Governo e a iniciativa privada. Definia, o campo de ação da iniciativa privada e se delimitava objetivamente o âmbito de atuação direta do Estado, coordenando estes dois setores de modo a evitar atritos ou excessos de investimentos simultâneos a absorverem fatores de produção limitados, gerando pressões inflacionárias. Tratava-se de um plano objetivo realista, capaz de conduzir a resultados positivos.
} 
O que se observa é que o esforço brasileiro no sentido de viabilizar melhores condições em CT\&I se amparou em Políticas Públicas ${ }^{3}$ que foram avançando na medida em que o tempo foi passando. Foram criados novos artefatos ${ }^{4}$ que visavam promover a atividade inovativa. Uma das formas como essa promoção acontece é através dos incentivos fiscais às empresas que inovam, onde se enquadra a Lei do Bem.

Pelo fato de ser um incentivo fiscal, há um rigoroso controle da Receita Federal. Isso faz com que a empresa se cerque de ferramentas que facilitem a busca de provas que afirmem sua regularidade. Nesse caso, aconselha-se, no próprio FORMP\&D:

Para uma boa gestão tecnológica e controle do programa de PD\&I nas empresas é fundamental uma perfeita articulação entre o gestor, a área técnica executora das atividades de PD\&I e os setores contábil e jurídico das mesmas. A identificação e comprovação dos dispêndios e investimentos em PD\&I, controlados contabilmente em contas específicas, bem como o preenchimento do formulário de envio das informações anuais ao MCTI será facilitada se a empresa tiver um programa de PD\&I formalizado por escrito, contendo todos os projetos, com indicação dos dispêndios planejados e realizados, no que se refere a pessoal próprio alocados nas atividades de PD\&I, em tempo integral ou parcial, serviços de terceiros (realizados por universidades e instituições de pesquisa, inventores independentes ou microempresas e empresas de pequeno porte), materiais de consumo, além dos investimentos em bens de capital e intangíveis. (MCTI, 2013a, p. 2).

Complementando, Zucchi expõe que há uma exigibilidade implícita de uma gestão mais rigorosa nas práticas relacionadas à atividade inovativa:

Normalmente, tratam-se de normas detalhadas, complexas e, muitas vezes subjetivas e que acarretam ou mesmo exigem a adoção de controles e trabalhos adicionais contábeis e extra-contábeis, e, mesmo, algumas vezes, a contratação de consultorias especializadas. (ZUCCHI, 2011, p. 19).

Portanto, deve estar bem claro para os gestores que a empresa estará sujeita às inspeções e verificações pertinentes. Por esse motivo:

A utilização do incentivo fiscal envolve um processo decisório no qual devem ser analisadas diversas informações e situações que incluem: informações contábeis sobre os dispêndios realizados nos projetos; análise técnica dos projetos considerados, que normalmente são alterados anualmente; avaliação do risco fiscal, uma vez que não há uma prévia aprovação por parte do governo para a utilização do incentivo; avaliação do custo da implantação dos procedimentos necessários para a obtenção do incentivo em comparação com a diminuição da carga tributária a ser obtida; projeção de resultados. (ZUCCHI, 2011, p. 23).

Logo, não trata-se apenas de redução de gastos. Ao considerar o contexto em que se inserem os processos empresariais, a tomada de decisão, muitas vezes, sofre influências alheias aos dados quantitativos. Esse fato torna a análise qualitativa mais ampla e capaz de captar nuances que fogem aos números e suas representações, conforme Zucchi (2011, p. 27) afirma:

Analisar resultados numéricos é uma tarefa que parece mais objetiva do que entender processos. Quando resultados numéricos são analisados estão envolvidas variáveis quantitativas, entretanto, quando se trata de processos empresariais, deve-se levar em consideração que o comportamento humano ocorre dentro de um determinado contexto organizacional, formado por pressões ambientais, políticas, sociais, estruturais, etc., cujas variáveis normalmente são mais subjetivas e de natureza qualitativa”.

\footnotetext{
${ }^{3}$ Ver: Avellar (20007), Kannebley Jr. e Porto (2012), Almeida (2009), Viotti (2008).

${ }^{4}$ Em Avellar (2007): Plano de Desenvolvimento Tecnológico Industrial (PDTI) e Agropecuário (PDTA).
} 
A interpretação complexa e dúbia requer cuidados na hora de preencher o formulário e mesmo de definir o processo de inovação, pois todas as informações são passíveis, de explicação e, que, trazem consequências:

O resultado é uma insegurança que beira ao medo do empresário por equívoco se apropriar de algum benefício fiscal que seja passível de glosa e consequente autuação pelo fisco. Na dúvida, ele deixa de aplicar o benefício em prejuízo ao projeto. (DENHARDT, 2013, p. 82).

\section{Procedimentos Metodológicos}

Com o objetivo de identificar quais são os benefícios resultantes da Lei Bem na atividade inovativa da firma percebidos por empresas localizadas no Rio Grande do Sul (RS) no período de 2006 a 2012, optou-se pela realização de um estudo de múltiplos casos.

Com a intenção de traçar um corte temporal relacionado à frequência da utilização dos benefícios fiscais da Lei do Bem, selecionou-se o período de sete anos, ou seja, as empresas que interessavam à pesquisa eram aquelas que foram expostas ao benefício fiscal por um período longo. Assim, foram consideradas, para esta primeira triagem, a utilização do benefício pelas empresas entre o ano-base de 2006 até 2012 que no RAUIF foram publicadas de 2007 a 2013. Após a definição do período de análise, identificou-se que tanto a Região Sul quanto o RS ficam em segundo lugar em número de empresas beneficiais pela Lei do Bem no Brasil no período descrito.

Para escolher um grupo de empresas, verificou-se a frequência anual de uso da Lei do Bem. Assim, foram identificadas e escolhidas as empresas que haviam obtido a frequência de 7, 6 e 5 anos. Considerando tal critério, o grupo de empresas que interessava à pesquisa foi composto por 38 empresas, conforme apresentado no Quadro 1.

Quadro 1: Frequência das empresas alvo da pesquisa

\begin{tabular}{|c|c|}
\hline Frequência & $\mathbf{N}^{\mathrm{o}}$ de Empresas \\
\hline 7 vezes & 6 \\
\hline 6 vezes & 10 \\
\hline 5 vezes & 22 \\
\hline TOTAL & $\mathbf{3 8}$ \\
\hline
\end{tabular}

Fonte: Elaboração própria com base no MCTI (2006-2012)

Definida a população, a etapa seguinte foi a de realizar contato com as empresas e verificar a possibilidade de participarem da pesquisa. Os contatos aconteceram, primeiramente por e-mail, seguidos de ligações telefônicas. Em um primeiro momento se apresentava o objetivo da pesquisa e, posteriormente era enviado o roteiro da entrevista. Como resultado desse processo, das 38 empresas, 9 aceitaram participar da pesquisa, conforme descrito no Quadro 2.

Quadro 2: Informações das empresas que participaram da pesquisa

\begin{tabular}{|c|c|c|c|}
\hline $\begin{array}{c}\text { Frequência do uso da } \\
\text { Lei do Bem }\end{array}$ & $\mathrm{N}^{\circ}$ de Empresas & Município & CNAE \\
\hline 7 vezes & 3 & Caxias e Guaíba & 28 e 29 \\
\hline 6 vezes & 4 & Caxias e Canoas & 28 e 29 \\
\hline 5 vezes & 2 & Caxias e Igrejinha & 15 e 29 \\
\hline TOTAL & $\mathbf{9}$ & - & - \\
\hline
\end{tabular}

Fonte: Elaboração própria com base no MCTI (2006-2012)

Após a escolha das empresas respondentes, foi feita a elaboração de instrumento de pesquisa. No caso do estudo em questão, foi elaborado um roteiro de perguntas abertas com 20 perguntas relacionadas 
ao incentivo fiscal/FORMP\&D e mais 11 perguntas referentes à atividade inovativa realizada pela empresa.

A etapa de pré-teste foi realizada no início de maio de 2015. Após essa fase, foram feitos ajustes no instrumento de pesquisa e um novo roteiro com 27 perguntas sobre incentivo fiscal/FORMP\&D e 9 perguntas sobre à atividade inovativa realizada pela empresa serviu de base para as entrevistas seguintes.

Foram realizadas entrevistas com nove empresas, sendo que quatro delas fazem parte de um mesmo grupo empresarial e, assim, esse grupo será considerado como uma única empresa. Importante destacar que, embora o RAUIF seja público, com os nomes das beneficiárias constando em todos os anos pesquisados, as empresas preferiram manter sigilo quanto à divulgação do seu nome no estudo aqui apresentado. Por isso, ficou estabelecido que seriam usados nomes fictícios (optou-se por nomes de jóias brasileiras): Ágata, Ametista, Esmeralda, Jaspe, Magnetita, Ônix, Rubi, Safira e Turmalina. Como foi levado em consideração o grupo que continha quatro empresas, buscou-se uma alternativa: foram agrupadas as sílabas iniciais nos nomes fictícios para representá-las, ficando 'Sarujasam' (Safira+ Rubi+Jaspe+ Ametista).

Foram entrevistadas diferentes pessoas nas empresas analisadas e aquelas diretamente envolvidas com a execução e o controle de informações referentes aos dispêndios da atividade inovativa e com o preenchimento do FORMP\&D. Todas as entrevistas foram gravadas e transcritas e tiveram, em média, 1,5 hora de duração. Geralmente os respondentes eram dois e representam as áreas envolvidas com a questão da inovação e obtenção de incentivo fiscal. As áreas de ocupação mais frequentes dos respondentes eram contabilidade e finanças, seguidas pelas áreas de planejamento e engenharia.

\section{Influência dos incentivos fiscais da Lei do Bem na atividade inovativa de firmas industrias}

\subsection{Atividades de inovação das empresas investigadas}

O objetivo deste tópico é avançar na análise das características das empresas, papel das atividades inovativas e investimentos em $\mathrm{P} \& \mathrm{D}$.

Considerando a importância de discutir as características da atividade inovativa das empresas entrevistadas, percebeu-se a presença de uma expressão que resume as considerações dos entrevistados: DNA. O DNA, em uma empresa, passa a ser determinante para o bom funcionamento e formação das peculiaridades que ela desenvolve ao longo do tempo, pois a bagagem que a sustenta passa a ser o ponto de partida para o aprendizado e evolução.

A partir das entrevistas pôde ser observado que as empresas consideram a atividade inovativa como um diferencial competitivo. Todas afirmaram que realizam tais atividades já há tempo e que isso é que garante sua manutenção e/ou crescimento no mercado. Na Magnetita afirmou-se que: "ela (a empresa) sempre trabalhou em cima disso, sempre evoluiu na parte de P\&D. E, geração após geração tudo isso, no fim, tem que diminuir custos e também melhorar o negócio da empresa. A gente trabalha para poder concorrer e poder gerar resultado".

Dessas colocações, originam-se os fundamentos para a inovação, pois, para que a empresa invista em novos produtos, ela tem que vislumbrar um ganho nisso. A constatação mais óbvia é aumentar o market share ou a lucratividade, seja por meio de redução nos custos ou aumento nas vendas.

A empresa Esmeralda trouxe, que: "está no DNA da empresa a questão da inovação". Isso significa dizer que a empresa tem em sua origem a inovação, pois sem ela não há empresa. Os fundamentos empresariais dessa entidade são calcados na inovação e, por ser um setor muito dinâmico, se ela não se organiza para ter inovações, ela está fora do mercado.

Pensando na trajetória da empresa, a entrevistada da Safirujasam afirmou: “a empresa foi evoluindo e foi investindo, inovando, pensando diferente". Ela acrescenta que: "esses incentivos do governo, eles despertaram mais interesse da empresa”.

Observa-se que, para se estabelecer uma cultura na empresa que gire em torno das atividades inovativas, é necessário que se tome por essencial o contínuo desenvolvimento de novas habilidades. Mas, fica evidente que quanto mais a empresa inova, mais fácil fica esse processo, ou pelo menos, com um grau de dificuldade menor. 
Pode-se atribuir essa facilidade no processo ao aumento no aprendizado dos colaboradores no que tange às exigências e detalhes da Lei. As pessoas envolvidas passaram a ter mais conhecimento das particularidades do princípio legal. Tal aprendizado levou a reflexos nos processos que foram baseados na aplicação das prerrogativas desse princípio.

Sob outra ótica, é deste cenário que inovar passa a ser uma busca constante, panorama que é retratado a partir de um olhar para o mercado, conforme explicou um dos entrevistados na empresa Magnetita: “a conexão com as necessidades do cliente é essencial”,

Esta noção também mostra-se presente na entrevista da empresa Esmeralda quando afirmou: “a empresa ganhou um prêmio por não ter reclamações, devido aos atendimentos com resposta. Isso se dá devido ao relacionamento com os clientes”.

Também foi olhando para as necessidades do mercado - agora através de um impeditivo legal que a Sarujasam afirmou: "aí a gente se adaptou e criou o novo”.

Tais constatações reforçam duas questões importantes: 1) o grupo analisado é composto por firmas que consideram a inovação como diferencial competitivo, onde inovar faz parte da atividade da firma e é entendido como fundamental, havendo, assim, uma relação entre ser direcionado para a inovação e utilizar o incentivo fiscal da Lei do Bem; e 2) na atividade inovativa dá-se ênfase às informações provenientes dos clientes e do mercado.

Ademais, mostra-se constante nesse ponto que, além da sua conservação como competidoras no mercado, as empresas buscam superar as expectativas dos clientes com alternativas inovadoras. Nesse sentido, elas procuram promover melhorias à sociedade, oferecendo produtos que não sejam agressivos à saúde das pessoas e que não prejudiquem o meio ambiente, e que supram as carências da vida moderna.

Então, todas elas, em um determinado momento, encaram a inovação como um diferencial competitivo que irá fazer a empresa se destacar das concorrentes - isso acontece no momento em que se oferece uma solução de ponta, que pode fazer com que os clientes reforcem as compras ou mesmo que haja a conquista de novos clientes em função dessa inovação.

Quando foi perguntado se 'a empresa passou a investir em P\&D devido ao surgimento da Lei do Bem no país?’, todas elas foram categóricas em negar tal ocorrência. Na empresa Magnetita afirmou-se: “Não, a empresa já investia antes”.

Na Ágata: “Não. Está na estratégia da empresa inovar, criar novos produtos, novas soluções para o mercado, é independente de lei. A empresa é inovadora por si só. Os investimentos não são decididos em função do benefício. O benefício já é automático, não é porque eu tenho benefício que eu vou dispender, vou produzir, vou criar um produto novo ou uma melhoria. O benefício é uma consequência disso aí. Então a decisão não está ligada ao benefício, ela é da empresa, é estratégia da empresa”. Na Esmeralda: “a empresa já tinha esse perfil de investimento para melhorar, alcançar mercados novos”.

Ao analisar as falas dos entrevistados, ficou clara a desvinculação entre inovação e Lei do Bem. Essa constatação se deve ao fato de que, em todas as empresas há uma necessidade de inovar e, havendo ou não o incentivo, elas continuarão a inovar.

Inovar é um fator competitivo. Uma vantagem que a empresa passa a ter no mercado e que, portanto, faz com que os benefícios sejam considerados como um plus, mas não a base para a inovação. O princípio legal não é um fator indutor da inovação. Mas, será que essa falta de vínculo é totalmente incapaz de promover mais inovações?

Se é fato que a inovação é necessária e, mesmo que as empresas aleguem que não há uma relação direta entre Lei do Bem e Inovação, pode-se considerar que indiretamente ela alavanca a inovação, pois quando a empresa cria rotinas de controle mais eficientes, ela passa a ter um aprendizado que é irreversível, o que promove sua evolução no contexto em que está inserida.

No roteiro da entrevista havia a pergunta: 'existe a prática na empresa de comparar os custos de um projeto com o uso da Lei do Bem e sem o uso da Lei do Bem?'. Nesse caso, as respostas variaram. Apenas uma empresa, a Magnetita, foi decisiva em dizer que compara: "os próprios engenheiros, sabedores do incentivo, já vem com a proposta de compra de alguma coisa com o comparativo”.

Na Ágata, a resposta foi mais ampla: “o que a área tributária fala pro pessoal da engenharia? Por exemplo: a engenharia está projetando para contratar 3 pessoas (está no budget). Eu falo: não deixa pra janeiro. Contrata em dezembro, porque a Lei do Bem é bem clara: tem um mínimo de benefício que ela 
me dá: eu aproveito 60\% das despesas se eu manter o meu nível de emprego. Se eu começar o ano com 100 funcionários e terminar o ano com esses mesmos 100 - eu recebo no mínimo 60\%, mas se eu disser que eu comecei o ano com 100 e terminei o ano com 101, eu recebo $70 \%$ e se eu disser que terminei o ano com 105, eu recebo 80\%”.

E, explicando porque não consegue fazer o comparativo, na Ônix afirmou-se: "não tem uma margem com linearidade estável. Há oscilações no lucro”.

Como pode ser observado, não há uma resposta que seja decisiva, pois para que as empresas passem a comparar um projeto com ou sem o uso dos benefícios proporcionados pela Lei do Bem, deveria haver uma linearidade nos lucros da empresa, além de um conhecimento mais profundo das possibilidades de utilização desses benefícios.

Para que isso aconteça na empresa, deve-se observar a cultura da mesma, assim como o nível de conhecimento da Lei dentre os envolvidos nos projetos. Todos possuem clareza quanto às particularidades da norma? O que mostra-se presente é que aumentando o contato dos colaboradores com a Lei, ela passará a ser uma rotina na empresa, o que possibilitará um maior aproveitamento de seus benefícios.

Logo, pode até ser que não haja o vínculo aparente, mas são “dois rios que vão desaguar no mesmo oceano”, ou seja, a inovação dentro da empresa e a Lei do Bem vão se encontrar em algum momento lá na frente. Assim, a norma legal - mesmo que indiretamente - é capaz de promover mais inovações.

Um outro enfoque no que se refere ao investimento em $P \& D$ estava na pergunta 'Como é decidido o quanto será destinado anualmente para os investimentos em P\&D?’, novamente, não houve uma regularidade nas respostas.

Na Magnetita: "sempre pensam em relação ao orçamento do produto, assim já há uma estimativa, um percentual, com o qual a empresa tenta se equiparar aos níveis de investimento mundial”.

Na Sarurajam: "há um percentual de aproximadamente 1,5\%, mas que pode variar em função da conjuntura. Atualmente, em função da crise, já se reduziu bastante. Até porque foram cortados os investimentos e mesmo que o governo diga que está incentivando, eu não tenho recurso para investir e então a gente está segurando bastante”.

Na Ônix: "No Planejamento Estratégico eles definem quais são os produtos que eles vão desenvolver e é um valor específico que pode ser gasto naquele projeto. Mas é um valor que às vezes, no decorrer do projeto, dependendo da decisão da direção, pode se reduzir ou aumentar. O planejamento é feito no final do ano anterior ao projeto, mas essa decisão pode ser tomada a qualquer momento depois que iniciou o ano, de acordo com faturamento, mercado, projeto”.

No geral, o que se pode constatar é que não há um percentual fixo, parece haver uma flexibilização no que tange aos investimentos em inovação. Essa variação decorre em função de fatores como a situação macroeconômica do setor e do país, onde se observa a conjuntura na qual a empresa está inserida para a tomada de decisão quanto ao valor investido. Porém, há uma outra variável que mostra-se mais importante nessa decisão, que é a situação financeira da empresa. Porém, é inevitável a correlação entre esses dois componentes da tomada de decisão.

\subsection{Questões relativas ao uso da Lei do Bem}

A título de organização, serão analisadas as questões referentes ao uso da Lei do Bem no que tange a: período de uso; clareza nas instruções; linguagem adequada; alterações no FORMP\&D; responsabilidade pelo preenchimento; rotinas e identificação de projetos de cunho inovador; reconhecimento do profissional que trabalha com projetos inovadores; e efeitos paralelos às exigências da Lei.

Em se tratando do período de uso - o qual é apresentado pelo Relatório Anual de Uso dos Incentivos Fiscais -, busca-se averiguar porque existem espaços em branco na escala de tempo analisada quanto às empresas selecionadas. Todas as entrevistadas confirmaram as datas previamente levantadas através neste relatório.

Foram observadas duas situações: i) a empresa possui lacunas na linha de tempo em foco; e ii) a empresa aparece pela primeira vez depois do início da Lei do Bem. Quanto à primeira situação, ou seja, 
às lacunas que intercalam o período, percebe-se que: ou a empresa teve projetos negados nessa época (portanto, não aprovados pelo MCTI) ou então ela não auferiu lucro naquele ano (não se beneficiando do incentivo fiscal). Dessa forma, não foi possível fazer nenhuma apreciação, em função de que a informação a respeito do lucro no período não foi fornecida pelas empresas, assim como a questão referente aos projetos negados pelo MCTI e os respectivos pretextos pelos quais isso aconteceu.

Entretanto, em relação à segunda situação - onde a empresa aparece pela primeira vez depois do início da Lei do Bem (2007 ou 2008, ou seja, um ou dois anos depois) - as informações fornecidas pelas entrevistadas foram capazes de conferir coerência às ações apresentadas. Todas seguem a mesma linha de raciocínio: suspeita quanto à veracidade dos benefícios e à automaticidade no processo de utilização dos mesmos.

Nas palavras da Ágata: “Tinha uma lei antiga - a do PDTI, só que nós não utilizávamos, pois era mais complexa, pois tinha que mandar um projeto pro governo. Hoje não, tu gasta e já utiliza o benefício. Daí ele devia ser aprovado e só depois tu fazia o pedido. Poucas empresas utilizavam isso. Hoje, não, tu gastou, tu te beneficia”. Na empresa Magnetita, o argumento seguiu a mesma lógica: “Quando a lei foi aprovada, foi uma surpresa e não se acreditava que era assim, tanto que eu tenho dúvida se vai continuar assim”.

A desconfiança que permeava as empresas na época resume o sentimento unânime delas. Isso aconteceu devido ao fato de que antes da entrada em vigor da Lei do Bem havia o PDTI, o qual - para que a empresa se beneficiasse - passava primeiramente pelo crivo do MCTI, para só então ser divulgado se a empresa se beneficiaria ou não. Com a Lei do Bem o incentivo é automático, inclusive esse é um dos pontos fortes desse benefício. Portanto, a incredulidade das empresas foi uma constante nesse começo da Lei.

A suspeita quanto aos reais benefícios propostos às empresas foi tão grande que as levou à busca de assessorias externas.

No roteiro da entrevista constava uma pergunta sobre a clareza das instruções da Lei e todas as empresas foram veementes em negar a clareza, mas a fala da Ônix resume a percepção de todas elas: "Se fosse super-clara, não se teria uma consultoria”. Na Ágata: "para nos ajudar, nós temos um consultor para a montagem do processo". Na Magnetita aconteceu da mesma forma, pois a empresa já conhecia internamente a Lei e a consultoria ajudou a montar o processo: “eles estão mais no dia a dia em várias empresas, então tem mais ideias, e tem mais contato com o mercado a respeito do que está sendo colocado. E é mais um esclarecimento da lei em si: tirando dúvidas sobre a legislação e o entendimento do fisco sobre a legislação”. Na Ônix a visão foi complementar às ideias das empresas anteriores: "porque o conhecimento é limitado. E pegando terceiros, eles têm vários clientes, então vai formando um conceito. É tudo mais fácil.”.

Sintetiza-se, a partir das contribuições dos entrevistados, que as empresas já conheciam a Lei do Bem - até mesmo porque setores como a Contabilidade e Financeiro têm a obrigação de atualizar-se (inclusive possuem informativos para isso), mas, a desconfiança em relação à mesma fez com que essas empresas fossem buscar ajuda externa. Essa desconfiança foi gerada pela falta de clareza no princípio legal em relação às exigências na comprovação do que é relacionado efetivamente à atividade inovativa.

Alega-se que as consultorias possuem um conhecimento mais amplo, em função do contato com diversas empresas e os problemas relativos à utilização do benefício. Portanto, para um primeiro momento, as consultorias foram úteis para dar o start no processo e também para trazer confiança quanto à capacidade que a empresa tinha de utilizar os benefícios proporcionados pela Lei do Bem. Passou a ser quase um desafio para aqueles que estavam imbuídos em entender como funcionava a lei e como as outras empresas estavam usando-a.

Todas as empresas entrevistadas ainda usam algum serviço prestado por essas consultorias nos dias atuais, porém, o contrato de serviço reduziu-se muito, ficando mais a questão de revisões para as consultorias, que dão o aval final para que o FORMP\&D seja enviado ao MCTI. Nesse ponto, as empresas e os profissionais envolvidos com a Lei do Bem tiveram que aprender a lidar com as exigências previstas na norma, adaptando os processos e aculturando a empresa no sentido de viabilizar o uso dos benefícios trazidos pela norma legal.

Outro agravante e talvez o mais inquietante seja a linguagem que deve estar no FORMP\&D. 
Como a Lei do Bem é abrangente, a Sarujasam exprime suas preocupações: "No início a gente não tinha a clareza, era uma coisa muito genérica (...) e agora com as análises do ministério, é uma questão bem conceitual. Teria que ser o mesmo conceito, mas não é palpável”.

Essa busca de uma linguagem comum entre empresas e MCTI é reforçada pela Sarujsam: “então, eles (do Ministério) têm dificuldade de entender e, às vezes, o que a gente descreve não é compreensível. E essas coisas que não são palpáveis, que não tem como colocar no papel como uma mudança de layout que gerou uma melhoria no processo de produção ou uma situação em que um pesquisador foi compreender um fenômeno da natureza, ficando várias horas no campo acompanhando. Como é que eu coloco isso no papel e o técnico que vai lá um ano depois, um ano e meio depois? Ele vai dizer: não, imagina se vai gastar todas essas horas pra entender esse fenômeno. É esse tipo de questionamento que vem e que está distante de uma compreensão". Na mesma empresa se levantou a questão: "eles não estão na empresa para entender, pois é um conceito, é a interpretação. Fica muito dentro de uma subjetividade da empresa”. E complementa: “Então, nós que temos uma estrutura boa, com assessoria, mesmo assim a gente fica receoso e não consegue fazer uma coisa certa, porque pode vir alguém questionar e entender diferente”. Isso acontece em função de que: "as regras não são claras. Não tem uma diretriz clara e também eu entendo que não tem como escrever tudo, pela diversidade que tem de produtos e tipos de pesquisas". Assim: "fica na mão do contribuinte ele arriscar ou o quanto ele acha que tem que arriscar e se assessorar para chuvas e trovoadas".

Tais considerações são o reflexo de uma característica da Lei do Bem, que é a sua abrangência. Essa amplitude, ao mesmo tempo em que é um fator positivo - não beneficiando nenhuma empresa ou setor em especial - também confere uma falta de direcionamento, o que é a causa de maiores dificuldades quanto ao enquadramento das atividades empresariais sob a ótica inovativa.

Outro tópico importante foi levantado no que tange ao FORMP\&D é a divulgação do Relatório pelo MCTI na empresa Sarujasam: “O ministério, todo ano - até 2012 -, analisava os nossos projetos, despesas, dispêndios e aprovava ou não. E, através de uma listagem que ele publicava, algumas empresas não apareciam. A partir de 2013, o que ele faz? Eles analisam integralmente o relatório (tem uma portaria) e emitem um parecer e tu tens 30 dias para te explicar, porque se não foi aprovado, foi porque tinha alguma inconsistência. Aí também é uma listagem que é publicada, só que agora ela é publicada em lotes”.

Esse trecho da entrevista mostra exatamente a situação até o último ano do período em análise, que é 2012. As empresas que constavam no Relatório eram as que tiveram seus projetos automaticamente aprovados. Após 2013, a comunicação entre MCTI e beneficiárias mudou, passando a ser transmitido à empresa o resultado negativo da análise feita pelo MCTI, onde a empresa tem até 30 dias para responder pelas incoerências apontadas.

No que tange, ainda, ao FORMP\&D, a maioria das empresas pesquisadas não possui uma área exclusiva para a Lei do Bem. Elas encarregam uma área de compilar as informações. Na Magnetita, a resposta à pergunta sobre quem seria o responsável pelo preenchimento do foi: "É o analista de planejamento, com o contador e o gerente tributário. Mas tem a parte de engenharia, por que tem questões de descrição do projeto.” Na Ágata: “é a área de impostos diretos quem preenche”. Na Turmalina: “Cada área e os responsáveis de cada área e a controladoria tem a responsabilidade de prestar contas à consultoria através de planilhas eletrônicas”. Na Esmeralda: “eles nos ajudam e ajudam a fazer a tradução da linguagem do nosso setor com os termos técnicos”. Na Ônix: “usa-se planilha eletrônica para controle das horas dos engenheiros, o que cada colaborador está fazendo em que trabalho, que projeto que ele está trabalhando, em cada dia do mês, depois em cada mês do ano. Então, é um controle diário em cima de cada projeto. É assim que eu faço o controle, depois a gente compila todas as áreas que estão envolvidas (...) e eles reportam à contabilidade a quantidade de horas. O RH nos manda e já está tudo mapeado: a parte de RH, engenharia, terceiros. E nós preenchemos o formulário com o detalhamento dos projetos e mandamos para a auditoria conferir". Na Sarujasam: "Se pensarmos no passado, a gente encontrava as informações e a assessoria preenchia, colocava no formato. Atualmente, é a gente que faz tudo isso. Nós vamos entender os conceitos, nós vamos fazer o nosso relatório. Então, a engenharia de projetos faz a sua parte (tem as fotos e tudo estruturado). Depois a gente converte no formato do relatório. 
É a contabilidade, que transmite o formulário (a consultoria revisa). É basicamente engenharia e contabilidade, mas é uma orientação da área tributária”.

Assim, constata-se que há o compartilhamento das informações com os setores que possuem coparticipação nos projetos: engenharia e RH. Entretanto, é da área Contábil ou Financeira o fechamento do processo para posterior verificação de inconsistências - principalmente em relação aos termos que são mais apropriados e condizentes aos projetos - pela consultoria.

As colocações dos entrevistados mostram uma evolução em termos de aprendizado, pois - num primeiro momento - as empresas deixavam todo o processo aos cuidados da consultoria, o que não ocorre plenamente nos dias de hoje. Atualmente, todas se amparam na assessoria para uma conferência e possível adequação dos termos mais técnicos relacionados a projetos na Lei do Bem, mas ressalte-se que houve uma redução significativa em termos dos serviços contratados desses terceiros, devido ao aumento do esclarecimento em relação à Lei.

Esse entendimento foi uma demanda suprida internamente, pois não houve, em todas as empresas, a criação de um departamento específico responsável pela Lei do Bem. A Ágata trouxe: “a gente vai se aprimorando nessa questão de Lei do Bem que é complexa e dá um retorno muito bom. Não foi criado um departamento, mas nós começamos a criar controles de forma que a gente tem que ter a informação mais precisa para uma eventual fiscalização de mostrar para o fisco. Caso haja uma despesa vinculada à $P \& D$ em uma fiscalização, haverá as provas dessas despesas”. Na mesma linha, a Esmeralda alegou: "Foram criados muito controles, os quais ajudaram a organização. Começamos a controlar o tempo de trabalho das pessoas nos projetos para fazer uma avaliação do perfil dos nossos colaboradores”.

Em se tratando da necessidade da implantação de processos inexistentes na rotina da empresa, a Ágata trouxe: "Pela própria característica de controlar muito essa parte financeira, foi muito fácil a adoção da Lei do Bem. Não foi a Lei do Bem que fez com que nós realizássemos toda a parte de processos. os processos já existiam com uma performance e uma eficiência e nós melhoramos a entrega. E a eficiência nos processos trouxe a facilidade da adoção da lei do bem”. Corroborando com a citação acima, na mesma empresa - a Ágata - foi explicado: “Nós, da área tributária somos consultores internos desse pessoal e duas ou três vezes por ano a gente faz reuniões e chama todo o pessoal envolvido e explica a lei de novo, o que é a lei para deixar na cabeça deles. É importante que vocês anotem, preencham tudo certinho e que aloquem corretamente. É educação continuada. Mostra-se a contribuição deles para esse processo. Daí há o reforço quanto ao preenchimento da planilha e possível fiscalização”.

Pode ser observado que as colocações anteriores retratam uma condição singular em que a empresa se coloca como uma gestora do conhecimento a ser passado para os colaboradores. Ao saber da finalidade de todos os controles, o processo fica mais claro e os envolvidos passam a verificar a sua contribuição nas atividades inovativas da empresa. Esse envolvimento é um fator relevante, pois faz com que a capacidade de aprendizado coletivo aumente, tornando a empresa mais dinâmica.

Fica evidente que há uma trajetória pré-existente, onde a empresa já possui uma base para a implantação de novos controles, porém, sustentados por uma plataforma já instalada, que são as rotinas. Dessa forma, é a capacidade que a empresa possui - através do uso da Lei - de extrair o máximo de vantagem possível da situação, pois ao familiariza-se com o princípio legal, ela passa a visualizar novas aplicações para aqueles controles antes vistos apenas como exigências para o benefício. $\mathrm{O}$ uso consciente traz mais eficiência e acaba otimizando as tarefas rotineiras.

Para que a empresa se beneficie, ela tem que se organizar e criar rotinas que lhe sejam úteis em algum momento. Na Magnetita foi respondido que "a empresa se organiza para alocar e conhecer custos, tendo controle de quanto custa cada projeto”. Para o preenchimento do FORMP\&D, os apontamentos de horas e despesas, assim como a guarda de toda prova para uma possível fiscalização tiveram que se tornar “cultura, hábito e costume dentro da empresa”, como afirma-se na empresa Esmeralda.

Em uma análise mais pontual, pode-se observar que a empresa que se atém a olhar seus processos, com vistas apenas às exigências legais, perde a oportunidade de focar-se em melhorias em relação à rotina que ela tem. Em várias das entrevistas levantou-se a questão de que esses controles beneficiaram a empresa de outras formas que não apenas àquela vinculada à exigência adjacente à lei.

Na empresa Ônix foi tratado o processo que envolve os benefícios da Lei do Bem como “trabalhoso”. Porém, as entrevistados na Esmeralda acabaram deixando explícito que as melhorias 
oriundas da utilização da Lei existem: "pois agora a gente já pensa em se policiar para identificar os possíveis projetos”. Na Ônix foi dito: “A gente conseguiu se organizar mais e melhor, fazer um controle da gestão de projetos, e que em termos de horas não era tão bem detalhado. Então acabei melhorando a gestão dos meus projetos em relação a isso”. Na Sarujasam a entrevistada ponderou que: “Até pouco tempo a gente não tinha esse controle das horas (...) a gente começou a criar apontamentos, que serviram para saber também a performance do profissional (...) isso gerou outras informações para a gestão, na verdade”.

Analisando em partes, pode-se observar que quando a empresa antevê uma vaga possibilidade de considerar um projeto como inovador, ela agora já se prepara de uma forma mais adequada à lei, pois aprendeu que deve se resguardar de possíveis fiscalizações fazendo um portfólio de todo o projeto guardando o máximo de informações sobre ele -, e, conforme as entrevistadas, é o que acontece, pois eles possuem uma espécie de dossiê com tudo aquilo que é relacionado ao projeto, como fotos e planilhas de controle. Essa ação, embora tenha uma base legal para a empresa também passa a ser um histórico de projetos que podem ter dado certo e outros que careceram de detalhamento maior, mas que podem, em outro momento vir a calhar e quem sabe apresentar-se como inovação para o alinhamento da lei.

Outro reflexo que emergiu das entrevistas foi a questão da performance do profissional, a qual passa a ser mais visível em relação aos projetos que ele participa. É claro que pensar no retorno financeiro é natural, comparando custo versus benefício, mas foi ressaltada a valorização do profissional que se envolve em atividades inovativas. Na Esmeralda afirmou-se que: "O profissional de mercado hoje não está preparado para ter que prestar contas neste nível”. É significativa a relutância que os envolvidos com a inovação - pelo menos em um primeiro momento - possuem. Na visão deles é um incômodo "eles se sentem um pouco monitorados”.

Para contornar essa situação, a empresa lidou com o viés comportamental, como mostram as próximas palavras: "então teve um aspecto que a gente teve que trabalhar bem antes para mostrar para as pessoas que ninguém estava preocupado em medir o desempenho do profissional, mas que a gente precisaria demonstrar para um terceiro em caso de fiscalização (...) então nós trabalhamos essa parte emocional (...) para as pessoas perceberem isso sem causar uma frustração ou um desgaste”. E foi o que acabou sendo feito. Constata-se, nesse caso uma mudança de cultura e de rotina na empresa, pois a mesma teve que se reposicionar para seguir em frente com as exigências da Lei e mostrar para os envolvidos que era importante o comprometimento deles no desenvolver do processo.

A empresa tinha a consciência de que haveria colaboradores relutantes, mas ela buscou uma via que tornasse claro o benefício para ambas as partes - tanto para a empresa como para o trabalhador. Tanto que, nas palavras das entrevistadas: "a aderência depois da exposição das causas foi de 100\%. Algumas pessoas num primeiro momento se atrapalharam, mas depois a aderência foi grande.”

A atenção que foi dada aos trabalhadores foi extremamente importante para o sucesso da caminhada nas atividades inovativas da empresa, pois os profissionais que faziam parte dos projetos não sabiam o quão importante era a sua participação - por menor que fosse. Complementam essa respeitável participação em projetos de $P \& D$, quando as entrevistadas afirmam que: "Principalmente porque eles se sentiram reconhecidos como profissionais diferenciados para o mercado, porque eles estão acostumados a trabalhar com a lei da inovação”.

A empresa leva os resultados aos colaboradores dos projetos que eles se engajam, como uma forma de dar um feedback e se ampara na presunção de que o profissional que faz parte desses momentos possui um diferencial: "Então tiramos todo esse aspecto de controle, foi bem ligado à colaboração, 'porque eu tenho algo a mais que o mercado não tem, eu sei trabalhar com as regras da inovação da Lei do Bem’. E, para finalizar, essa questão na Empresa Esmeralda foi ponderado: "Nós estimulamos isso, é o reconhecimento de um profissional que está acima da média do mercado".

Quanto às outras entrevistadas, nenhuma delas ressaltou de forma tão explícita como no parágrafo anterior a Esmeralda trouxe. Não há nenhuma formalização da participação dos colaboradores nos projetos inerentes à Lei do Bem nas outras empresas.

Então, a empresa passa a ver que num horizonte além das exigências legais da Lei do Bem, há um efeito paralelo que possibilita uma organização mais eficiente em sua capacidade inovativa e capaz de promover o aprendizado por meio do seu negócio e do que é necessário para que ele sobreviva em meio à 
acirrada concorrência, como constatou a entrevistada da Sarujasam: “o contexto todo vai levar a inovar mesmo que não tenha nenhum incentivo porque vai ser um meio de sobrevivência”.

O investimento em inovação, para os entrevistados da Ágata: "não é o fim, mas ele vem como resultado”. Para os entrevistados da Ônix, ele pode até "não ser decisório”, mas a empresa sabe de sua repercussão no mercado. Consequentemente, como alega a entrevistada da Sarujasam, a Lei do Bem: "é um estimulador para fazer inovações", pois mesmo havendo aquele dispêndio, "eu sei que eu vou investir e uma parte retorna”. Essa visão é o que torna a Lei interessante do ponto de vista organizacional, pois ela oferece à empresa uma possibilidade de estrutura-se de forma enxuta e dessa maneira, além de beneficiarse da redução da carga tributária, passa a utilizar as exigências da lei como um portal para novos investimentos. E, pode até ser que não seja reinvestido o valor da redução de impostos, mas é generalizada a noção de que sem inovar a empresa perderá mercado. A seguinte fala - da Ônix evidencia um ponto de vista bem genérico: “aí estão duas coisas que o governo não gostaria de ouvir: que a gente não depende da lei do bem para fazer pesquisa e desenvolvimento e que ela não retorna para investimento em pesquisa e desenvolvimento".

É notório o olhar das empresas mais direcionado à redução da carga tributária, mas fica evidente que novas atividades inovativas são reforçadas pela existência da Lei do Bem. Conforme mostra a seguinte fala: "numa discussão de orçamento alega-se que a inovação que eu fiz no ano passado gerou uma economia de impostos para a empresa de tanto, então, vamos renegociar a minha fatia do bolo, nesse sentido é um argumento". Essa empresa, que era a Sarujasam corrobora com a Magnetita, pois elas compactuam da mesma fala: "pelo menos na parte da argumentação a lei do Bem ajuda a argumentar a investir”. Percebe-se que ao se tornar um argumento, a Lei do Bem passa a ser um catalisador de novas formas, novos aprendizados, novos posicionamentos e lá no final de novos produtos e processos.

A capacitação de pessoal que a lei traz implícita é um fator preponderante, que, mesmo a duras penas - em função das reclamações pelos controles que são cobrados e que são provas cabais - acaba sendo um ponto nevrálgico do uso dos incentivos da Lei do Bem. Ao provar a participação de mais pessoas com formação nos projetos de P\&D, a empresa pode se beneficiar da redução tributária, o que, em última instância, gera caixa. Na empresa Magnetita se afirmou em relação aos benefícios da Lei que: "a valorização da classe, principalmente de engenharia, os pesquisadores, a organização da empresa em controles, a facilidade na aprovação de novos projetos” são pressupostos que fazem com que a Lei do Bem seja um produto muito bem aceito pelas usuárias.

\section{Considerações Finais}

A realização da pesquisa de campo permitiu observar que as seis empresas analisadas utilizam de forma intensa a Lei do Bem. Destaca-se, neste aspecto, a presença de elementos específicos à amostra, o que torna as constatações advindas desse estudo únicas e idiossincráticas.

Nas entrevistas feitas, observou-se que a Lei do Bem é um instrumento de incentivo que visa beneficiar as empresas que fazem PD\&I com regularidade e não apenas aquelas que fazem uso oportunista do instrumento. Constou-se ainda que, havendo ou não a Lei do Bem, as firmas permaneceriam na busca pela inovação; que inovar é fundamental para manter e obter vantagem competitiva e que os investimentos nesta atividade são definidos mais pela dinâmica de mercado do que pela existência de incentivos públicos. Assim, os benefícios são considerados como algo adicional, mas não a base para a inovação, demonstrando que o incentivo legal não revelou-se um fator determinante para a realização da inovação pelas firmas investigadas.

É necessário, portanto, que haja um olhar mais amplo quando da avaliação de uma ação normativa que possui como objetivo incentivar à inovação através de P\&D. Certamente há benefícios concretos na adoção da Lei do Bem, mas entende-se que esses transcendem o campo tributário.

Neste trabalho, adotou-se com um caminho para essa reflexão a avaliação quanto aos benefícios diagnosticados, que, por sua vez, são oriundos da Lei do Bem e de suas exigências, ou seja, o nosso entendimento é que há indiretamente a promoção à atividade de inovação na firma, por meio da utilização do princípio legal. 
Os pontos positivos em relação à Lei foram muitos, mas, o que mais sobressaiu foi o da redução tributária, que é considerado um benefício pecuniários de destaque para as empresas. Dentre outros pontos positivos, relacionados ao impacto da atividade inovativa na rotina da firma, foram encontrados quatro: 1) adoção de controles; 2) confiança derivada das rotinas; 3) organização facilitadora; e 4) experiência reconhecida dos profissionais envolvidos nos projetos de pesquisa e desenvolvimento para geração da inovação.

A Lei do Bem é relativamente nova, completando, em 2015, dez anos. Cabe, portanto, reforçar a necessidade de uma verificação mais contundente na avaliação dos resultados esperados pela criação de políticas públicas voltadas ao fomento à inovação. Ficam algumas questões em aberto que precisam de respostas: os benefícios estão trazendo os resultados esperados pela política? Será que a 'Lei do Bem' beneficia as empresas mais preparadas para gerar inovação? Toda essa reflexão demanda um olhar mais amplo em relação aos ganhos existentes pelo uso da Lei.

Um dos achados da pesquisa trata da pouca relação entre o incentivo e o aumento dos gastos privados em inovação, retratado pela posição das empresas quando falavam que já investiam em inovação mesmo antes da lei e que, mesmo na ausência dela continuariam a investir. Refletir sobre o uso da Lei e o provável beneficiário é uma tarefa que carece de maiores informações, mas que são essenciais para o amadurecimento do objetivo da norma pública. Possivelmente, haveriam resultados mais concretos se houvesse algum mecanismo capaz de fazer a conexão direta entre o valor economizado no pagamento de impostos e o redirecionamento de tais valores.

Em relação às limitações do estudo, constataram-se duas vertentes. Quanto à primeira, observa-se que as empresas ainda veem a academia distante - distante de suas práticas e de suas buscas. Essa constatação deriva da falta de aceitação por parte das empresas na realização da entrevista. A pesquisa poderia ter seguido outro caminho, caso todas as ligações feitas e emails enviados trouxessem uma resposta afirmativa. As conclusões poderiam ter sido outras, caso mais empresas tivessem aceitado o convite para participar, dando oportunidade para se estudar, analisar e identificar relações com o que se percebe na teoria.

Ultrapassada essa primeira limitação, a segunda relaciona-se à falta de abertura das empresas no que tange às informações de cunho quantitativo. $\mathrm{O}$ argumento para a negativa foi que valores eram informações estratégicas e, mesmo a pesquisadora oferecendo sigilo e dizendo que as informações seriam agregadas, a maioria das empresas não aceitou informá-los. Contudo, mesmo apresentando limitações, há que se considerar que o avanço dos estudos sobre incentivos fiscais à inovação possui, ainda, uma ampla possibilidade de pesquisas. Não sendo estas de abrangência apenas ao âmbito da Economia, mas também de outras áreas do conhecimento como a Administração, a Contabilidade e Direito.

No que diz respeito às sugestões para novas pesquisas, a partir do que foi constatado no presente estudo, tem-se duas que apontam para uma reflexão mais ampla: Em termos de incentivo fiscal à inovação, ainda existe espaço para estudos que relacionam a análise de dados quantitativos complementados com análises qualitativas. Como um avanço nesta área poderia ser discutido o papel da Lei e os efeitos que ela promove (crowding-out ou crowding-in ) frente ao entendimento dos benefícios aqui proposto. Outra sugestão seria relativa à segmentação por atividades em uma amplitude maior - seja por região ou mesmo no Brasil, que revelaria mais padrões de comportamento em relação aos benefícios que são propostos pela Lei do Bem.

\section{Bibliografia}

ALVARENGA, G. V. Impactos dos fundos setoriais nas empresas: Novas perspectivas a partir da função dose-resposta. Dissertação de Mestrado, UNB/Brasília, 2011.

ARAÚJO, B.C et al. Impactos dos fundos setoriais nas empresas. Texto para discussão número 1737. Rio de Janeiro, IPEA, 2012.

AVELLAR, A.P. Avaliação de Políticas de Fomento à Inovação no Brasil: impacto dos incentivos fiscais e financeiros em 2003. Tese de Doutorado, IE/UFRJ, 2007. 
Avaliação do impacto do PDTI sobre o gasto em atividades de inovação e em P\&D das empresas industriais. (Cap.8). In: Negri J.A; Kubota, L.C. (orgs). Políticas de Incentivo à Inovação Tecnológica. Brasília, DF: IPEA, 2008.

Avaliação de Políticas de Apoio à Inovação no Brasil: Impactos dos Incentivos Fiscais e Incentivos Financeiros. Prêmio CNI de Economia, 2008a.

BRASIL. (1988). Constituição da República Federativa do Brasil. Brasília, DF, Senado, 2014. . (2006). Lei $\mathrm{n}^{\circ} 11.196$ de 21 de novembro de 2005. Dos incentivos à inovação tecnológica. Capítulo III. Presidência da República. Disponível em: <planalto.gov.br>. Acesso em 14/09/2014. CALMANOVICI, Carlos Eduardo. A inovação, a competitividade e a projeção mundial das empresas brasileiras. Rev. USP [online]. 2011, n.89, pp. 190-203. ISSN 0103-9989.

CASSIOLATO, José Eduardo; LASTRES, Helena M. Martins. Sistemas de inovação e desenvolvimento: as implicações de política. Revista São Paulo em Perspectiva, v. 19, n. 1, p. 34-45, jan./mar. 2005. CASTRO, D.V.; LEAL, E.A.S.; LANNES, P.A.; REGIO, R.L.S. Políticas de incentivo à inovação: hipóteses para não adesão empresarial à Lei do Bem. IX Simpósio Excelência em Gestão e Tecnologia. Disponível em < http://www.aedb.br/seget/artigos12/37316729.pdf> Acesso em 01/08/2014. CCGE (2010). LIVRO AZUL. Livro Azul da $4^{\text {a }}$ Conferência Nacional de Ciência e Tecnologia e Inovação para o Desenvolvimento Sustentável - Brasília: Ministério da Ciência e Tecnologia/Centro de Gestão e Estudos Estratégicos, 2010.

DOSI, G. (1984). Mudança Técnica e Transformação Industrial: a teoria e uma aplicação à indústria dos semicondutores. Campinas, SP: Editora da Unicamp, 2006.

FURTADO, J. (2004) Padrões de inovação brasileira. Disponível em: <http://www.ifhc.org.br/wpcontent/uploads/apresentacoes/1941.pdf>. Acesso em 26/07/2015.

GIL, A. C. Como elaborar projetos de pesquisa. 4a ed. São Paulo: Atlas, 2008.

GODOY, A.S. Introdução à pesquisa qualitativa e suas possibilidades. Revista de Administração de Empresas (RAE). São Paulo, v. 35. Mar./Abr. 1995.

GRIZENDI, E. Manual de orientações gerais sobre inovação. Ministério das Relações exteriores. Brasília, 2011.

GUIMARÃES, E.A. Políticas de inovação: financiamento e incentivos. (Cap.4). In: Negri J.A; Kubota, L.C. (orgs). Políticas de Incentivo à Inovação Tecnológica. Brasília, DF: IPEA, 2008.

IBGE (2011). PINTEC. Disponível em: <http://www.pintec.ibge.gov.br>Acesso: 07/09/2014.

KANNEBLEY JR., S.; PORTO, G. Incentivos Fiscais à Pesquisa, Desenvolvimento e Inovação no Brasil. Uma avaliação das Políticas Recentes. Banco Interamericano de Desenvolvimento (BID). 2012.

LUNA, F.; MOREIRA S.; GONÇALVES A. Financiamento à inovação. (Cap. 5). In: Negri J.A; Kubota, L.C. (orgs). Políticas de Incentivo à Inovação Tecnológica. Brasília, DF: IPEA, 2008.

MCTI (2007). Relatório anual da utilização dos incentivos fiscais - ano base 2006. CAP. III DA LEI DO BEM - LEI No 11.196/05. Brasília - DF, dezembro 2007.

(2008). Relatório anual da utilização dos incentivos fiscais - ano base 2007. CAP. III DA LEI DO

BEM - LEI No 11.196/05. Brasília - DF, dezembro 2008.

(2009). Relatório anual da utilização dos incentivos fiscais - ano base 2008. CAP. III DA LEI DO

BEM - LEI No 11.196/05. Brasília - DF, dezembro 2009.

(2010). Relatório anual da utilização dos incentivos fiscais - ano base 2009. CAP. III DA LEI DO

BEM - LEI No 11.196/05. Brasília - DF, dezembro 2010.

(2011). Relatório anual da utilização dos incentivos fiscais - ano base 2010. CAP. III DA LEI DO

BEM - LEI No 11.196/05. Brasília - DF, dezembro 2011.

(2012). Relatório anual da utilização dos incentivos fiscais - ano base 2011. CAP. III DA LEI DO

BEM - LEI No 11.196/05. Brasília - DF, dezembro 2012.

(2013). Relatório anual da utilização dos incentivos fiscais - ano base 2012. CAP. III DA LEI DO

BEM - LEI No 11.196/05. Brasília - DF, dezembro 2013.

(2013a). Formulário anual da utilização dos incentivos fiscais - ano base 2013.

(2015). Notícia sobre os Comitês de Auxílio Técnico (CATs). Disponível em: <

http://www.mcti.gov.br/noticias/-/asset_publisher/IqV53KMvD5rY/content/nota-de-esclarecimento-dasetec-sobre-a-avaliacao-de-projetos-no-ambito-da-lei-do-bem>. Acesso em 10/06/2015. 
NELSON, R.; WINTER, S. (1982). Uma teoria evolucionária da mudança econômica. Campinas, SP: Editora da UNICAMP, 2005.

NONAKA, I.; TAKEUCHI, H. (1995). Criação de conhecimento na empresa: Como as empresas japonesas geram a dinâmica da inovação. Rio de Janeiro, RJ: Editora Elsevier, 1997.

OCDE (2002). Manual de Frascati: proposta de diretrizes para coleta e interpretação de dados sobre inovação tecnológica. São Paulo: F-iniciativas, 2013. (para a tradução brasileira).

(2005). Manual de Oslo: proposta de diretrizes para coleta e interpretação de dados sobre inovação tecnológica. Rio de Janeiro: FINEP, 2005. (para a tradução brasileira).

PACHECO, C.A. As reformas da política nacional de Ciência, Tecnologia e Inovação no Brasil (19992002). CEPAL. Santiago do Chile: 2002.

. Desafios da inovação: incentivos para a inovação: o que falta ao Brasil. Instituto de

Estudos para o Desenvolvimento Industrial (IEDI): 2010.

PENROSE, E. The theory of the growth of the firm. Oxford: Basil Blackwell, 1959.

Procuradoria Geral da Fazenda Nacional. (2015). Certidões de regularidade fiscal. Disponível em:

$<$ http://www.pgfn.fazenda.gov.br/divida-ativa-da-uniao/todos-os-servicos/informacoes-e-servicos-parapessoa-fisica/certidoes-de-regularidade-fiscal/certidao-conjunta>. Acesso: 20/04/2015.

QUEIROZ, S. (2006). Aprendizado Tecnológico. In PELAEZ, V.; SZMRECSÁNYI, T. Economia da Inovação Tecnológica. São Paulo: Hucitec.

RAPINI, M. S. Padrão de financiamento aos investimentos em inovação no Brasil. Belo Horizonte:

UFMG/CEDEPLAR, 2013.

RFB (2011). Receita Federal do Brasil. Instrução Normativa IN nº 1.187/2011. Disciplina os incentivos fiscais à PD\&I. Disponível em:

$<$ http://normas.receita.fazenda.gov.br/sijut2consulta/link.action?visao=anotado\&idAto=16160> . Acesso em 10/03/2015.

ROCHA, F. Does governmental support to innovation have positive effect on R\&D investments? Evidence from Brazil. Revista Brasileira de Inovação. Campinas (SP), 14, n. esp., p. 37-60, julho 2015.

ROSENBERG, N. (1982). Por Dentro da Caixa-Preta: tecnologia e economia. Campinas, SP: Editora da Unicamp, 2006 (para a tradução brasileira).

SALERNO, M.S.; KUBOTA, L.C. Estado e inovação. (Cap.1). In: Negri J.A; Kubota, L.C. (orgs). Políticas de Incentivo à Inovação Tecnológica. Brasília, DF: IPEA, 2008.

SALERNO, M. S.; DAHER, T. Política industrial, tecnológica e de comércio exterior do governo federal (PITCE): Balanço e Perspectivas. Disponível em:

$<$ http://www.desenvolvimento.gov.br/sistemas_web/renai/public/arquivo/arq1272980896.pdf $>$. Acesso em: 08/09/2014.

SALLES FILHO, S. Política de Ciência e Tecnologia no I PND (1972/74) e no I PBDCT (1973/74). Revista Brasileira de Inovação. Campinas (SP). Vol. 1. Número 2 Julho/Dezembro de 2002.

Política de Ciência e Tecnologia no II PBDCT (1976). Revista Brasileira de Inovação. Campinas (SP). Vol. 2. Número 1 Janeiro/Junho de 2003.

Política de Ciência e Tecnologia no III PBDCT (1980/85). Revista Brasileira de

Inovação. Campinas (SP). Vol. 2. Número 2 Junho/Dezembro de 2003a.

TIDD, J.; BESSANT, J.; PAVITT, K. Gestão da Inovação, Porto Alegre: Bookman, 2008.

TIGRE, P. B. Inovação e teorias da firma em três paradigmas. Revista de economia contemporânea. $n^{\circ} 3$, 1998.

VIOTTI, E. \& MACEDO, M. (orgs.) (2003). Indicadores de Ciência, Tecnologia e Inovação no Brasil Campinas, SP: Editora Unicamp.

YIN, R. K. Estudo de caso: planejamento e métodos. Porto Alegre: Bookman, 2010.

WEISZ, J. Mecanismos de apoio à Inovação Tecnológica. Brasília: SENAI 2006.

ZAWISLAK, P. A.; BORGES, M; WEGNER, D; SANTOS, A.; CASTRO-LUCAS, C. Towards the Innovation Function. Disponível em: < http://www.jotmi.org/index.php/GT/article/view/art94/459 >. Acesso: 09/01/2014. 
ZUCOLOTO, G. F. Desenvolvimento tecnológico por origem de capital no Brasil: P\&D, patentes e incentivos públicos. Rio de Janeiro: UFRJ, 2009. $211 \mathrm{f}$. Tese (Doutorado em Economia). UFRJ, Rio de Janeiro: 2009.

Lei do Bem: impactos nas atividades de P\&D no Brasil. Revista Radar. Instituto de Pesquisa Econômica Aplicada - IPEA 2010. Disponível em: <

http://www.inova.unicamp.br/inovacao/report/inte-radar6-ipea_leidobem100322.pdf >. Acesso em 10/02/2015. 